Shinji Takahashi MD, Yoshitaka Fujii MD, Shin-ichi Inomata MD, Masayuki Miyabe MD, Hidenori Toyooka MD

\section{Landiolol decreases a dysrhythmogenic dose of epinephrine in dogs dur- ing halothane anesthesia}

Purpose: To examine the effect of landiolol (ONO-I IOI), a new ultra-short acting and highly selective beta, blocker, on epinephrine-induced ventricular arrhythmias in halothane- anesthetized dogs.

Methods: We administered five different doses $\left(0,0.1,0.5,1.0,10 \mu \mathrm{g} \cdot \mathrm{kg}^{-1} \cdot \mathrm{min}^{-1}\right)$ landiolol and determined the dysrhythmogenic dose of epinephrine (DDE), defined as the smallest dose producing four or more PVCs within I5 sec, at each dose of landiolol and after cessation of infusion.

Results: The control value of DDE during 1.3 MAC halothane anesthesia was $1.26 \pm 0.44$ (mean \pm SD) $\mu \mathrm{g} \cdot \mathrm{kg}^{-1} \cdot \mathrm{min}^{-1}$ and the corresponding plasma concentration of epinephrine (PCE) was $12.2 \pm 8.3 \mathrm{ng} \cdot \mathrm{ml}^{-1}$. Concomitant administration of $10 \mu \mathrm{g} \cdot \mathrm{kg}^{-1} \cdot \mathrm{min}^{-1}$ landiolol increased DDE and corresponding PCE $(P<0.05)$. At 30 min after cessation of landiolol infusion. DDE and corresponding PCE returned to the control values.

Conclusions: Landiolol, at a dose of $10 \mu \mathrm{g} \cdot \mathrm{kg}^{-1} \cdot \mathrm{min}^{-1}$, has an antiarrhythmic effect on epinephrine-induced ventricular arrhythmias in dogs during anesthesia with halothane.

Objectif : Évaluer l'effet du landiolol (ONO-1/01), un nouveau bêta, bloquant hypersélectif et à action très brève, sur les arythmies ventriculaires induites par l'épinéphrine chez des chiens sous anesthésie à l'halothane.

Méthode : On a administré cinq dose différentes de landiolol $\left(0 ; 0,1 ; 0,5 ; 1,0 ; 10 \mu \mathrm{g} \cdot \mathrm{kg}^{-1} \cdot \mathrm{min}^{-1}\right)$ et déterminé la dose d'épinéphrine dysrythmogénique (DED), définie comme la plus petite dose pouvant produire au moins quatre ESV (extrasystoles ventriculaires) en moins de $15 \mathrm{~s}$ à chaque dose de landiolol et après l'arrêt de la perfusion.

Résultats : La valeur témoin de la DED pendant l'anesthésie avec 1,3 CAM d'halothane a été de I,26 $\pm 0,44$ (moyenne \pm écart-type) $\mu \mathrm{g} \mathrm{kg}^{-1} \cdot \mathrm{min}^{-1}$ et la concentration d'épinéphrine plasmatique (CEP) correspondante a été de $12,2 \pm 8,3 \mathrm{ng} \cdot \mathrm{ml}^{-1}$. Ladministration concomitante de $10 \mu \mathrm{g} \cdot \mathrm{kg}^{-1} \cdot \mathrm{min}^{-1}$ de landiolol a augmenté la DED et la CEP correspondante $(P<0,05)$. Trente minutes après l'arrêt de la perfusion de landiolol, la DED et la CEP correspondante ont retrouvé les valeurs témoins.

Conclusion : Une dose de $10 \mu \mathrm{g} \cdot \mathrm{kg}^{-1} \cdot \mathrm{min}^{-1}$ de landiolol a contré l'arythmie ventriculaire induite par l'épinéphrine chez des chiens sous anesthésie avec de l'halothane.

From the Department of Anaesthesiology, University of Tsukuba, Institute of Clinical Medicine, Tsukuba, Ibaraki, 305-8575, Japan. Address correspondence to: S Takahashi MD, Department of Anaesthesia and Critical Care Medicine, Tsukuba Gakuen Hospital, Tsukuba, Ibaraki, 305-0854, Japan. Phone: 81-298-36-9597; Fax: 81-298-36-9583; E-mail: shinjitk@db3.so-net.ne.jp Accepted for publication February 18, 1999 
B ETA blockers have been widely used for treatment of systemic hypertension, angina pectoris and tachyarrhythmias. " Various types of beta antagonists have been developed, but their use has been limited because of undesirable properties, prolonged hypotension and myocardial depression, which is attributed to their long duration of action. Zaroslinski and co-workers ${ }^{2}$ have demonstrated that esmolol, an ultra-short acting, highly cardioselective beta-adrenergic receptor antagonist is effective for the treatment of critically ill patients. Several investigators have also documented that it controls hemodynamic changes in clinical situations. ${ }^{3-5}$ Landiolol (ONO-1101), another ultra-short acting beta-receptor blocker, (2,2-dimethyl-1,3-dioxolan-4Syl-methyl 3-[P-\{3-\{(2-(morpholinocarbonyl-amino) ethyl) amino (-2S-hydroxypropoxy $/$ phenyl] propionate hydrochloride), has more potent cardiac activity than esmolol, ${ }^{6}$ and has been developed for application in emergency treatment of tachyarrhythmias in animals. ${ }^{6-8}$ However, there have been no studies that evaluated the effects of landiolol on epinephrine-induced arrhythmias and cardiac function. The purpose of this study, therefore, was to determine whether landiolol decreases the dysrhythmogenic doses of epinephrine, defined as the smallest dose producing four or more premature ventricular contractions within $15 \mathrm{sec}$, in halothane anesthetized dogs.

\section{Methods}

The study protocol was approved by our institutional animal care committee. Ten adult mongrel dogs of either sex and weighing 10-15 kg were anesthetized with $25 \mathrm{mg} \cdot \mathrm{kg}^{-1}$ pentobarbital ip. The trachea of each animal was intubated with a cuffed endotracheal tube, and the lungs were mechanically ventilated (Harvard Model $613^{\mathrm{TM}}$ Apparatus Company, Chicago, USA) with tidal volume of $15 \mathrm{ml} \cdot \mathrm{kg}^{-1}$ at a respiratory rate sufficient to maintain normoventilation. End-tidal $\mathrm{CO}_{2}$ concentration was continuously monitored. Anesthesia was maintained with $1.3 \mathrm{MAC}(1.1 \%$ at end-tidal concentration) halothane in oxygen. These concentrations were monitored by a respiratory/anesthetic gas analyser (Capnomac Ultima ${ }^{\mathrm{TM}}$, Datex instrumentarium, Helsinki, Finland) calibrated with a standard gas. The femoral artery and vein were cannulated for arterial blood pressure monitoring, blood sampling, and drug and fluid administration. Drug infusions were delivered via motor-driven syringe pumps (Termo Model STC-523 $3^{\text {TM }}$, Tokyo, Japan). The contralateral femoral vein was cannulated with a pulmonary artery catheter (Swan-Ganz Catheter ${ }^{\mathrm{TM}}$, Baxter Healthcare Corporation Edwards Critical-Care
Division, Santa Ana, CA, USA) for measuring pulmonary artery pressure, pulmonary capillary wedge pressure, central venous pressure, cardiac output and blood temperature (Cardiac Output Computer $7350^{\mathrm{TM}}$, Arrow, Reading, PA, USA). Lead II of the ECG was monitored continuously and recorded (Polygraph 7747 Amplifier Case ${ }^{\mathrm{TM}}$, San-ei, Tokyo, Japan). Additional monitoring included arterial blood gas analysis, electrolytes and hemoglobin concentration (Ciba Coring 288 Blood Gas System ${ }^{\mathrm{TM}}$, Ciba Corning Diagnostics Corp. Medfield, MA, USA). Maintenance fluid (Ringer's lactate solution) was administered at a rate of $10 \mathrm{ml} \cdot \mathrm{kg}^{-1} \cdot \mathrm{hr}^{-1}$. The metabolic acidosis noted with repeated epinephrine infusions was corrected with sodium bicarbonate as required. Serum potassium concentration was maintained between $3.5-4.5 \mathrm{mEq} \cdot \mathrm{l}^{-1}$ by infusing $\mathrm{KCl}$ as required. Arterial $p \mathrm{H}, \mathrm{PO}_{2}$, and serum sodium concentration were maintained within the range of 7.35$7.45,100-200 \mathrm{~mm} \mathrm{Hg}, 135-145 \mathrm{mEq} \cdot \mathrm{l}^{-1}$, respectively. During the study, blood temperature was maintained between $36.5-38.5^{\circ} \mathrm{C}$ using hot-water pad. After at least $90 \mathrm{~min}$ of stabilization of halothane-oxygen anesthesia, the following steps were undertaken.

The dysrhythmogenic dose of epinephrine was determined using the method described by Pace et al. ${ }^{9}$ This was defined as the smallest dose producing four or more premature ventricular contractions (PVCs) occurred within $15 \mathrm{sec}$ during three minutes epinephrine infusion (concentration $6 \mu \mathrm{g} \cdot \mathrm{kg}^{-1} \cdot \mathrm{ml}^{-1}$ ). The dysrhythmogenic dose of epinephrine was determined with standardized logarithmically spaced infusions of epinephrine lasting three minutes with $10-20 \mathrm{~min}$ recovery periods between infusions according to Pace et al. ${ }^{9}$ Recovery periods between infusions were allowed until the hemodynamic parameters returned to baseline levels. The infusion was started at a minimum dose $0.67 \mu \mathrm{g} \cdot \mathrm{kg}^{-1} \cdot \mathrm{min}^{-1}$ and was increased by $\mathrm{e}^{0.4}(\mathrm{e}=$ 2.72) until the dysrhythmia threshold was achieved. This procedure was repeated until the dysrhythmogenic dose of epinephrine was obtained. If dysrhythmias occurred at one of these doses, a smaller dose, divided by $\mathrm{e}^{0.2}$, was tested. When the criterion for dysrhythmogenic dose had been satisfied, an arterial blood sample was collected to measure the plasma concentration of epinephrine (PCE). During the recovery period, the epinephrine infusion was discontinued.

After determination of the dysrhythmogenic dose of epinephrine in the absence of landiolol, each dog was pretreated with landiolol. The infusion dose of landiolol was started at $0.1 \mu \mathrm{g} \cdot \mathrm{kg}^{-1} \cdot \mathrm{min}^{-1}$ and continued for 30 min to maintain a constant plasma concentration. This dose was based upon results from 
TABLE I Hemodynamic effects of landiolol during halothane anesthesia

\begin{tabular}{llllll}
\hline $\begin{array}{l}\text { Dose of Landiolol } \\
\left(\mu g \cdot \mathrm{kg}^{-1} \cdot \mathrm{min}^{-1}\right)\end{array}$ & $H R(\mathrm{bm})$ & $S B P(\mathrm{mmHg})$ & $D B P(\mathrm{mmHg})$ & $M B P(\mathrm{mmHg})$ & $C O\left(1 \cdot \mathrm{min}^{-1}\right)$ \\
\hline 0 & $145 \pm 31$ & $128 \pm 16$ & $86 \pm 14$ & $103 \pm 14$ & $2.24 \pm 0.50$ \\
0.1 & $131 \pm 11$ & $122 \pm 16$ & $86 \pm 16$ & $100 \pm 14$ & $1.79 \pm 0.60$ \\
0.5 & $131 \pm 11$ & $121 \pm 23$ & $83 \pm 15$ & $98 \pm 17$ & $1.61 \pm 0.42$ \\
1 & $134 \pm 7$ & $121 \pm 23$ & $80 \pm 19$ & $96 \pm 20$ & $1.54 \pm 0.36^{*}$ \\
10 & $121 \pm 6^{*}$ & $101 \pm 27^{*}$ & $64 \pm 22^{*}$ & $79 \pm 26^{*}$ & $1.19 \pm 0.44^{*}$ \\
30 min after cessation & $142 \pm 19$ & $119 \pm 23$ & $70 \pm 15^{*}$ & $90 \pm 16^{*}$ & $2.16 \pm 0.48$ \\
\hline
\end{tabular}

Hemodynamic values were obtained immediately before administration of epinephrine.

HR: heart rate, SBP: systolic blood pressure, DBP: diastolic blood pressure,

MBP: mean arterial pressure, CO: cardiac output.

Values, are expressed as mean $\pm \mathrm{SD}$.

* $P<0.05$ compared with landiolol 0 .

TABLE II Hemodynamic data after cessation of landiolol $10 \mu \mathrm{g} \cdot \mathrm{kg}^{-1} \cdot \mathrm{min}^{-1}$.

\begin{tabular}{clllll}
\hline & $H R(\mathrm{bm})$ & $S B P(\mathrm{mmHg})$ & $D B P(m m \mathrm{Hg})$ & $M B P(m m H g)$ & $C O\left(1 \cdot \mathrm{min}^{-1}\right)$ \\
\hline${ }^{\mathrm{a}}$ Landiolol $0 \mu \mathrm{g} \cdot \mathrm{kg}^{-1} \cdot \mathrm{min}^{-1}$ & $145 \pm 31$ & $128 \pm 16$ & $86 \pm 14$ & $103 \pm 14$ & $2.24 \pm 0.5$ \\
b Landiolol $10 \mu \mathrm{g} \cdot \mathrm{kg}^{-1} \cdot \mathrm{min}^{-1}$ & $118 \pm 6^{*}$ & $90 \pm 23^{*}$ & $55 \pm 17^{\star}$ & $69 \pm 21^{\star}$ & $1.26 \pm 0.51$ \\
10 min after cessation & $125 \pm 7$ & $109 \pm 20$ & $63 \pm 15^{*}$ & $81 \pm 16$ & $1.73 \pm 0.4$ \\
20 min after cessation & $134 \pm 13$ & $107 \pm 40$ & $68 \pm 15$ & $89 \pm 16$ & $2.02 \pm 0.47 \dagger$ \\
30 min after cessation & $142 \pm 19 \dagger$ & $119 \pm 23$ & $70 \pm 15$ & $90 \pm 16$ & $2.18 \pm 0.48 \dagger$ \\
\hline
\end{tabular}

a Obtained immediately before administration of epinephrine; ${ }^{b}$ Obtained immediately before cessation of landiolol.

HR: heart rate, SBP: systolic blood pressure, DBP: diastolic blood pressure, MBP: mean arterial pressure, CO: cardiac output.

Values, are expressed as mean $\pm \mathrm{SD}$.

* $P<0.05$ compared with landiolol 0 .

$\dagger P<0.05$ compared with landiolol $10 \mu \mathrm{g} \cdot \mathrm{kg}^{-1} \cdot \mathrm{min}^{-1}$.

preliminary experiments. After 30 min administration of landiolol, the procedure was repeated to determine the dysrhythmogenic dose of epinephrine in landiolol $0.1 \mu \mathrm{g} \cdot \mathrm{kg}^{-1} \cdot \mathrm{min}^{-1}$, starting at the control dysrhythmogenic dose of epinephrine.

Then, the dysrhythmogenic dose of epinephrine, in the presence of varying doses of $0.5,1.0$ and 10 $\mu \mathrm{g} \cdot \mathrm{kg}^{-1} \cdot \mathrm{min}^{-1}$ landiolol, was determined in the same way in the same dog. After landiolol was discontinued for $30 \mathrm{~min}$, the procedure to determine dysrhythmogenic dose of epinephrine was repeated, starting at the control dysrhythmogenic dose of epinephrine.

Blood samples for measuring the plasma concentration of epinephrine were withdrawn into plastic tubes containing EDTA-2Na. These were then centrifuged at $3000 \mathrm{rpm}$ for $10 \mathrm{~min}$ at $2^{\circ} \mathrm{C}$ to separate the plasma. For analysis of epinephrine, $1 \mathrm{ml}$ plasma was acidified by addition of $0.5 \mathrm{ml}$ perchloric acid $2.5 \%$ to precipitate protein. The samples were stored at $-40^{\circ} \mathrm{C}$ until analyzed. Epinephrine and norepinephrine concentrations in deproteinized plasma were determined by an automated double-column HPLC system (Model CA825 ${ }^{\mathrm{TM}}$,
Tosho Co.,Ltd., Tokyo, Japan). This assay system is based upon the trihydroxyindole reaction, and has a limit of sensitivity of $5 \mathrm{pg} \cdot \mathrm{ml}^{-1}$ for epinephrine and inter and intra-assay variations are less than $3 \%$.

Baseline values of hemodynamic variables at each landiolol concentration were recorded just before the administration of epinephrine. Hemodynamic data after cessation of landiolol were compared with the baseline values for $0 \mu \mathrm{gg} \cdot \mathrm{kg}^{-1} \cdot \mathrm{min}^{-1}$ landiolol and with the values obtained just before cessation of 10 $\mu \mathrm{g} \cdot \mathrm{kg}^{-1} \cdot \mathrm{min}^{-1}$ landiolol.

The data were expressed as mean \pm SD. Statistical analysis was performed using a commercially available software package (StatView ${ }^{\mathrm{TM}}$ Ver.4.5, Abacus Concepts, Inc., Berkeley, CA, USA). Data of the dysrhythmogenic dose of epinephrine and hemodynamic parameters, at different doses of landiolol were analyzed using analysis of variance (ANOVA) with Bonferroni's correction. $P$ value of $<0.05$ was considered significant. 


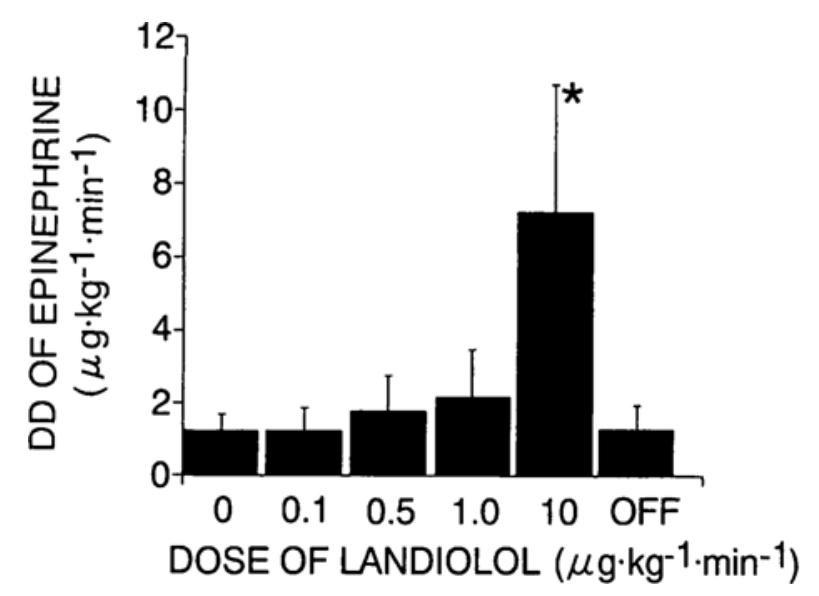

FIGURE 1 Dysrhythmogenic doses (DD) of epinephrine at the varying doses of landiolol pretreatments during halothane-oxygen anesthesia in dogs. OFF shows the DD of epinephrine of $30 \mathrm{~min}$ after cessation of landiolol infusion.(Mean $\pm S D$ ).

${ }^{*} P<0.05$ compared with no landiolol pretreatment (landiolol dose $=0$ ).

\section{Results}

The basal hemodynamic variables (data prior to epinephrine infusion) are shown Table I. Landiolol decreased HR, SBP, DBP, MBP and CO in a dose dependant manner. There were differences in these values when in $>1 \mu \mathrm{g} \cdot \mathrm{kg}^{-1} \cdot \mathrm{min}^{-1}$ landiolol was given for pretreatment. The control dysrhythmogenic dose of epinephrine was $1.26 \pm 0.44 \mu \mathrm{g} \cdot \mathrm{kg}^{-1} \cdot \mathrm{min}^{-1}$ and the corresponding plasma concentration of epinephrine was $12.2 \pm 8.3 \mathrm{ng} \cdot \mathrm{ml}^{-1}$ in $1.3 \mathrm{MAC}$ halothane anesthetized dogs. Pretreatment with landiolol enhanced the dysrhythmogenic dose of epinephrine and plasma concentration of epinephrine in a dose-dependent manner (Figures 1,2). The minimum effective dose was 10 $\mu \mathrm{g} \cdot \mathrm{kg}^{-1} \cdot \mathrm{min}^{-1}$. No arrhythmia was detected in two of ten dogs which received $11.02 \mu \mathrm{gg} \cdot \mathrm{kg}^{-1} \cdot \mathrm{min}^{-1}$ epinephrine during administration of landiolol 10 $\mu \mathrm{g} \cdot \mathrm{kg}^{-1} \cdot \mathrm{min}^{-1}$, the dysrhythmogenic dose of epinephrine in those cases was calculated as 11.02 $\mu \mathrm{g} \cdot \mathrm{kg}^{-1} \cdot \mathrm{min}^{-1}$.

After discontinuation of landiolol, hemodynamic variables were not different from control values. (Table II) Cardiac output increased $20 \mathrm{~min}$ after discontinuation of landiolol compared with that during $10 \mu \mathrm{g} \cdot \mathrm{kg}^{-1} \cdot \mathrm{min}^{-1}$ landiolol. Heart rate increased compared with that during $10 \mu \mathrm{g} \cdot \mathrm{kg}^{-1} \cdot \mathrm{min}^{-1}$ landiolol after $30 \mathrm{~min}$ after cessation. There were no increases in SBP, DBP, and MBP after cessation compared with that during $10 \mu \mathrm{g} \cdot \mathrm{kg}^{-1} \cdot \mathrm{min}^{-1}$ landiolol.

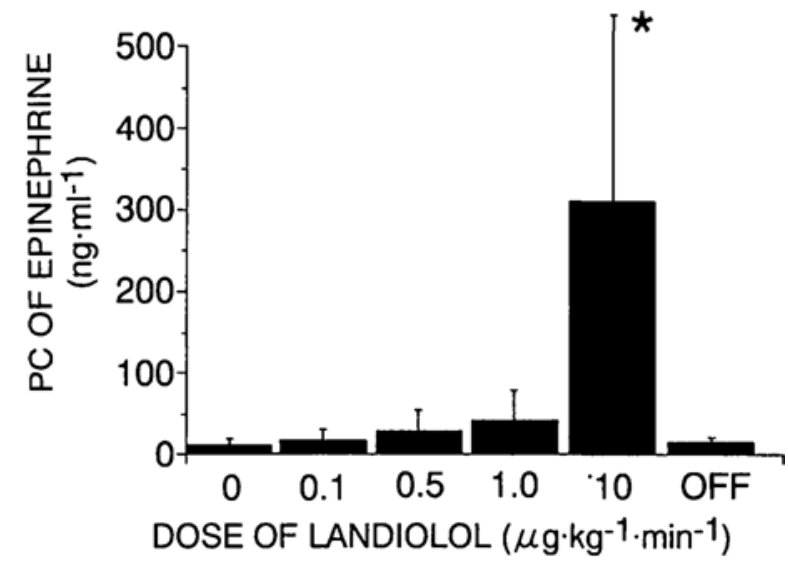

FIGURE 2 Plasma concentrations (PC) of epinephrine at the varying dose of landiolol pretreatments during halothane-oxygen anesthesia in dogs. OFF shows the PC of epinephrine of $30 \mathrm{~min}$ after cessation of landiolol infusion. (Mean $\pm S D$ ).

${ }^{\star} P<0.05$ compared with no landiolol pretreatment (landiolol dose $=0$ ).

\section{Discussion}

The major findings of this study were that pretreatment with $10 \mu \mathrm{g} \cdot \mathrm{kg}^{-1} \cdot \mathrm{min}^{-1}$ landiolol increased the threshold of dysrhythmogenic dose of epinephrine and plasma concentration of epinephrine, and was effective in suppressing hemodynamic variables, including $\mathrm{HR}$, SBP, DBP and CO.

The dysrhythmogenic doses of epinephrine were determined by a series of three minute infusions of epinephrine at least $10 \mathrm{~min}$ apart, which was similar to the method described by Pace $e t$ al. ${ }^{9}$ The control value of dysrhythmogenic dose of epinephrine $(1.26 \pm 0.44$ $\left.\mu \mathrm{g} \cdot \mathrm{kg}^{-1} \cdot \mathrm{min}^{-1}\right)$, in this study, was lower than in several previous reports $\left(2.07\right.$ to $3.23 \mu \mathrm{g} \cdot \mathrm{kg}^{-1} \cdot \mathrm{min}^{-1}{ }^{9-15}$ The reason for this difference remains unclear, but there are several possibilities. First, the pentobarbital used for animal preparation might affect the dysrhythmogenic dose of epinephrine, as thiopental, an ultra-short acting barbital, potentiates the epinephrine-induced arrhythmias in halothane-anesthetized in dogs. ${ }^{11}$ However, the experiments to determine the dysrhythmogenic dose of epinephrine were performed at least $90 \mathrm{~min}$ after the induction of anesthesia, to minimize the effect of pentobarbital on the dysrhythmogenic dose of epinephrine. Second, pancuronium bromide, used for muscle relaxation, has a vagolytic action, and Kamibayashi $e t$ al. ${ }^{16}$ demonstrated that the dysrhythmogenic dose of epinephrine was reduced by vagotomy. However, Schick $e t$ al. ${ }^{17}$ showed that pancuronium bromide did not affect 
dysrhythmogenic dose of epinephrine during inhalation anesthesia with halothane Thus, the effect of pancuronium bromide on the dysrhythmogenic dose of epinephrine is controversial. Third, fasting dogs, used in this experiment, might have a lower control dysrhythmogenic dose of epinephrine, since fasting reduces the arrhythmogenic dose of epinephrine in rats. ${ }^{18}$

Several investigators have studied the dysrhythmogenicity and prevention of epinephrine-induced arrhythmias during halothane anesthesia. ${ }^{12,13}$ Dimich $e t$ $a l^{12}$ demonstrated that esmolol prevented and suppressed arrhythmias in dogs during anesthesia with halothane, and also demonstrated that the dysrhythmogenic dose of epinephrine increased 10 -fold and 30 -fold above control values by administration of 150 $\mu \mathrm{g} \cdot \mathrm{kg}^{-1} \cdot \mathrm{min}^{-1}$ and $200 \mu \mathrm{g} \cdot \mathrm{kg}^{-1} \cdot \mathrm{min}^{-1}$ esmolol, respectively. ${ }^{12}$ We showed that the dysrhythmogenic dose of epinephrine increased 10 -fold above the control values with an infusion of $10 \mu \mathrm{g} \cdot \mathrm{kg}^{-1} \cdot \mathrm{min}^{-1}$ landiolol. Therefore, the antiarrhythmic effect of landiolol is 10 times greater than that of esmolol. This antiarrhythmic effect of landiolol might be due to high selectivity of beta, receptor antagonism.

The ratio of cardioselectivity (i.e., ratio of beta $_{1} /$ beta $_{2}$ potency) of landiolol (255) is higher than that of other beta receptor antagonists, such as esmolol (33) and propranolol (0.68). ${ }^{6}$ No studies have compared the effects of landiolol, esmolol, and propranolol, on the dysrhythmogenic dose of epinephrine. However, landiolol may be the most effective for preventing epinephrine-induced arrhythmias during anesthesia with halothane, based on this highly beta ${ }_{1}$ adrenoceptor selective feature.

Landiolol is unaffected by plasma esterase, and its elimination half-life is nine minutes. ${ }^{6}$ This elimination half-life is similar to that of esmolol, but is much shorter than that of propranolol ( $360 \mathrm{~min}) .{ }^{6}$ In this study, the inhibited hemodynamic variables returned to control values $\left(0 \mu \mathrm{gg} \cdot \mathrm{kg}^{-1} \cdot \mathrm{min}^{-1}\right.$ landiolol) $30 \mathrm{~min}$ after the end of landiolol administration. Thus, landiolol may be clinically useful because of its ultra-short acting properties.

In conclusion, landiolol is an antiarrhythmic agent for the management of epinephrine-induced ventricular arrhythmias in dogs during anesthesia with halothane.

\section{Acknowledgments}

The authors acknowledge Ono Pharmaceutical Co., Ltd. Osaka, Japan, for supplying landiolol (ONO-1101).

Refer.

1 Frishm

WH. Clinical differences between beta-

'ocking agents: implications for therapeutic substitution. Am Heart J 1987; 113: 1190-8.

2 Zaroslinski J, Borgman RJ, O'Donnell JP, et al. Ultrashort acting beta-blockers: a proposal for the treatment of the critically ill patient. Life Sci 1982; 31: 899-907.

3 Gold MI, Sacks DJ, Grosnoff DB, Herrington C, Skillman $C A$. Use of esmolol during anesthesia to treat tachycardia and hypertension. Anesth Analg 1989; 68: 101-4.

4 Dyson A, Isaac PA, Pennant JH, Giesecke AH, Lipton $J M$. Esmolol attenuates cardiovascular responses to extubation. Anesth Analg 1990; 71: 675-8.

5 Vucevic M, Purdy GM, Ellis FR. Esmolol hydrochloride for management of the cardiovascular stress responses to laryngoscopy and tracheal intubation. $\mathrm{Br} \mathrm{J}$ Anaesth 1992; 68: 529-30.

6 Iguchi S, Ipamura H, Nishizaki M, et al. Development of a highly cardioselective ultra short-acting $B$ - blocker, ONO-1101. Chem Pharm Bull Tokyo 1992; 40: 1462-9.

7 Muraki K, Nakagawa $H$, Nagano $N$, et al. Effects of ONO-1101, a novel beta-antagonist, on action potential and membrane currents in cardiac muscle. J Phrmacol Exp Ther 1996; 278: 555-63.

8 Motomura $S$, Hagihara A, Narumi $\Upsilon$, Hashimoto $K$. Time course of a new ultrashort-acting $B$ - adrenoceptor-blocking drug, ONO-1101: comparison with those of esmolol and propranolol by using the canine isolated, blood-perfused heart preparations. J Cardiovasc Pharmacol 1998; 31: 431-40.

9 Pace NL, Ohmura A, Wong KC. Epinephrine-induced arrhythmias: effect of exogenous prostaglandins and prostaglandin synthesis inhibition during halothane $-\mathrm{O}_{2}$ anesthesia in the dog. Anesth Analg 1979; 58: 401-4.

10 Kapur PA, Flacke WE. Epinephrine-induced arrhythmias and cardiovascular function after verapamil during halothane anesthesia in the dog. Anesthesiology 1981; 55: 218-25.

11 Hayashi $Y$, Sumikawa $K$, Yamatodani A, Tashiro $C$, Wada H, Yoshiya I. Myocardial sensitization by thiopental to arrhythmogenic action of epinephrine in dogs. Anesthesiology 1989; 71: 929-35.

12 Dimich I, Lingham R, Narang J, Sampson I, Shiang $H$. Esmolol prevents and suppresses arrhythmias during halothane anaesthesia in dogs. Can J Anaesth 1992; 39: 83-6.

13 Hayashi , Sumikawa K, Kamibayashi T, etal. Selective beta ${ }_{1}$ and beta ${ }_{2}$ adrenoceptor blockade on epinephrine-induced arrhythmias in halothane anaesthetized dogs. Can J Anaesth 1992; 39: 873-6.

14 Maze M, Smith CM. Identification of receptor mechanism mediating epinephrine-induced arrhythmias during halothane anesthesia in the dog. Anesthesiology 1983; 59: 322-6. 
15 Sumikawa K, Ishizaka N, Suzaki M. Arrhythmogenic plasma levels of epinephrine during halothane, enflurane, and pentobarbital anesthesia in the dog. Anesthesiology 1983; 58: 322-5.

16 Kamibayashi $T$, Hayashi $T$, Mammoto $T$, Tamatodani $A$, Sumikawa K, Toshiya I. Role of the vagus nerve in the antidysrhythmic effect of dexmedetomidine on halothane/epinephrine dysrhythmias in dogs. Anesthesiology 1995; 81: 992-9.

17 Schick LM, Chapin JC, Munson ES,Kushins LG. Pancronium, d-tubocurarine, and epinephrine-induced arrhythmias during halothane anesthesia in dogs. Anesthesiology 1980; 52: 207-9.

18 Miletich DJ, Albrecht RF, Seals C. Responses to fasting and lipid infusion of epinephrine-induced arrhythmias during halothane anesthesia. Anesthesiology 1978; 48 : 245-9. 